\title{
One Year of Laboratory Based COVID-19 Surveillance System in Belgium: Main Indicators and Performance of the Laboratories
}

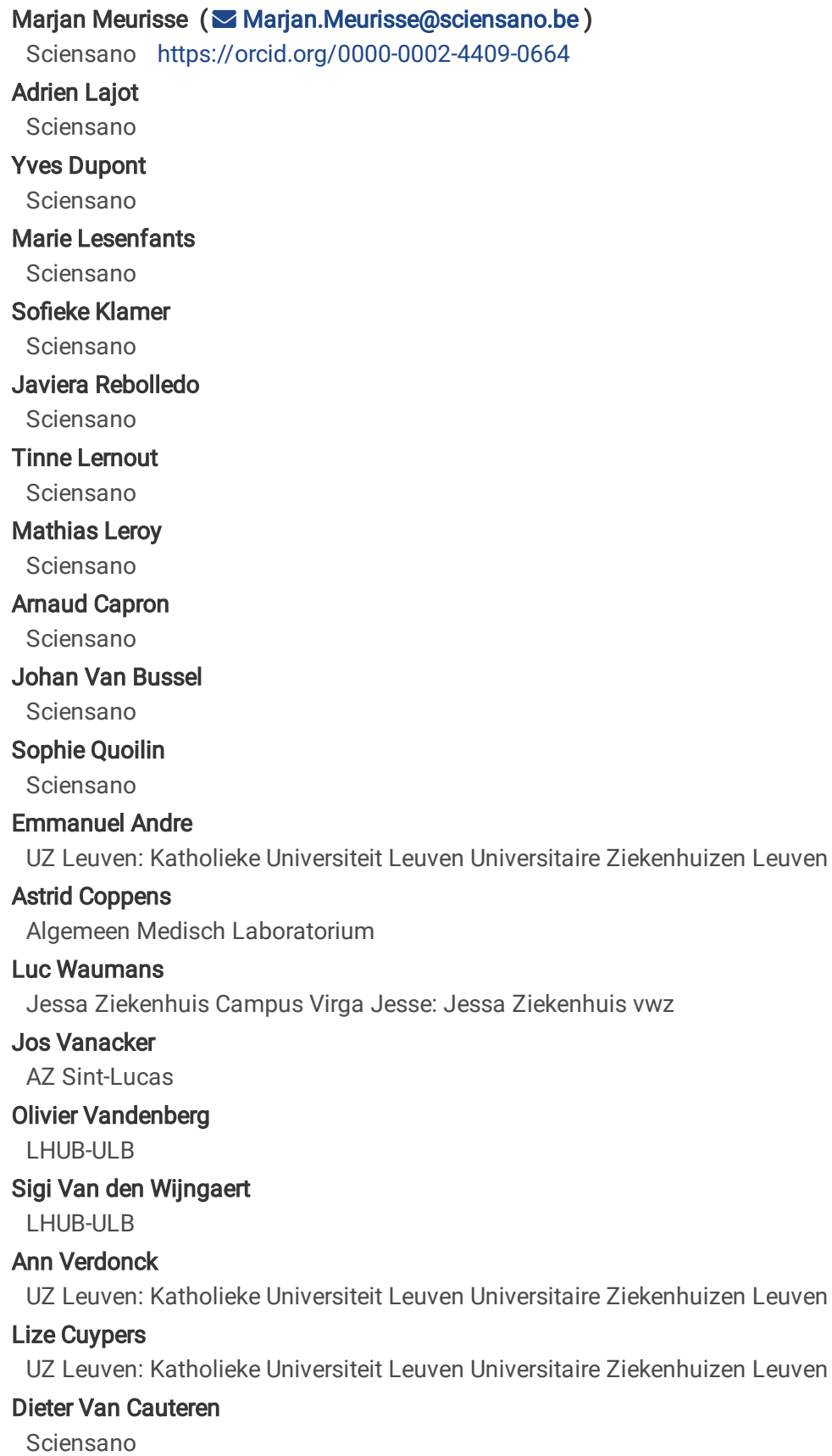




\section{Abstract}

Background: With the spread of coronavirus disease 2019 (COVID-19), an existing national laboratory based surveillance system was adapted to daily monitor the epidemiological situation of SARS-CoV-2 in the Belgium by following the number of confirmed COVID-19 infections, the number of performed tests and the positivity ratio. We present these main indicators of the surveillance over a one-year period as well as the impact of the performance of the laboratories, regarding speed of processing the samples and reporting results, for surveillance.

Methods: We describe the evolution of test capacity, testing strategy and the data collection methods during the first year of the epidemic in Belgium.

Results: Between the 1th of March 2020 and the 28th of February 2021, 9,487,470 tests and 773,078 COVID-19 laboratory confirmed cases were reported. Two epidemic waves occurred, with a peak in April and October 2020. The capacity and performance of the laboratories improved continuously during 2020 resulting in a high level performance. Since the end of November 202090 to $95 \%$ of test results are reported at the latest the day after sampling was performed.

Conclusions: Thanks to the effort of all laboratories a performant exhaustive national laboratory based surveillance system to monitor the epidemiological situation of SARS-CoV-2 was set up in Belgium in 2020. On top of expanding the number of laboratories performing diagnostics and significantly increasing the test capacity in Belgium, turnaround times between sampling and testing as well as reporting were optimized over the first year of this pandemic.

\section{Background}

The severe acute respiratory syndrome coronavirus 2 (SARS-CoV-2), identified in Wuhan end of December 2019, was first reported in Europe at the end of January 2020 [1-4]. The first coronavirus disease 2019 (COVID-19) case in Belgium was confirmed on the 3th of February 2020. This infected, but asymptomatic person, was one of the nine Belgians repatriated from Wuhan [5]. In March 2020, the first autochthonous infections were reported, followed by a sharp increase in the number of COVID-19 infections in Belgium [6].

With the spread of COVID-19, a close monitoring of this disease became necessary. In the frame of its surveillance activities, the department of Epidemiology and public health of Sciensano, the Belgian institute for health, progressively implemented the daily monitoring of the epidemiological situation of SARS-CoV-2 in the country through multiple surveillance systems from February 2020 onwards. One of these surveillance systems is a national laboratory based surveillance system $[7,8]$.

The main objective of the national laboratory based surveillance system of COVID-19 is to daily monitor the epidemic in Belgium by describing trends of virus circulation in the population over time. The most important indicators produced by this surveillance system are the number of confirmed COVID-19 infections, the number of performed tests and the positivity ratio, by age and geographical occurrence.

In this paper, we present these indicators over a 1-year period (1st of March 2020-28th of February 2021) in Belgium, taking into account the evolution of the laboratory test capacity and testing strategy during this period as well as the impact of performance of the laboratories regarding speed of processing the samples and reporting results to Sciensano for surveillance.

\section{Methods}

\section{Test capacity}

At the start of the COVID-19 epidemic early 2020, diagnostic testing for SARS-CoV-2 in Belgium was exclusively limited to the National Reference Centrum (NRC) for respiratory pathogens (University hospital of Leuven) [9]. With the rapid increase of the number of COVID-19 cases in the beginning of March, clinical microbiology laboratories (CML) also started to implement routine diagnosis of SARS-CoV-2 infection using home-made reverse transcription polymerase chain reaction (RT-PCR) assays. By the end of March, with the availability of commercial RT-PCR assays, more than 40 CML's were performing RT-PCR tests.

In reaction to the shortage of reagents and disposables, a federal testing platform using home-made reagents was set-up in the beginning of April 2020 to further increase the test capacity in Belgium. This platform consisted of a consortium of university hospitals, biotech, and pharmaceutical companies across Belgium, and was initially primarily dedicated to perform testing in long-term care facilities, and later also in other residential collectivities and sampling-triage centers [10]. In addition to increasing the test capacity, this platform also allowed to partially compensate the overflow encountered at CML level. It evolved in November 2020 to a new platform composed of 8 university laboratories linked to CML's qualified to perform SARS-CoV-2 RT-PCR assays (Fig. 1). These laboratories are geographically spread across the country to minimize logistic delays.

\section{Data collection and reporting}

Initially all positive samples for SARS-CoV-2 were sent to the NRC UZ Leuven for confirmation and the latter reported the confirmed COVID-19 cases to Sciensano. From the 15th of March 2020 onwards, laboratories implemented daily reporting of laboratory results directly to Sciensano without confirmation by the NRC [11]. Since April, test results of the federal testing platform were added to the test results reported by the NRC and the recognized clinical laboratories for molecular diagnosis of COVID-19 [12] (Fig. 1).

The implementation of a new laboratory based surveillance system and data collection was built upon the experience of the Belgian Sentinel Network of Laboratories (BSNL), established in 1983. This network, coordinated by Sciensano, is used to collect data on a weekly basis from laboratory confirmed 
cases of about 30 infectious diseases, reported by the participating sentinel laboratories [7, 13, 14]. For the laboratory based surveillance of COVID-19, daily reporting of all test results performed by CML's became mandatory for reimbursement [15-17] instead of the weekly and voluntary reporting of positive cases usually used by the BSNL [7].

Laboratories were required to report positive, negative and inconclusive test results of RT-PCR and antigenic diagnostic tests. Data on a selection of variables was collected as for the BSNL network: the date of sampling, the date of test result, the test result, the type of diagnostic test, a sample identification number, the laboratory identification number and patient demographic variables that allow identification of duplicate cases (i.e. postal code, date of birth and gender). Every day, from the beginning of March 2020 until the end of September 2020 incoming data from all recognized laboratories for COVID-19 testing in Belgium through the BSNL dataflow was processed by researchers at Sciensano and all data were centralized, stored on an SQL server and used for reporting.

Since the 5th of May, laboratories (NRC, CML's and federal testing platforms) were additionally asked to report their COVID-19 test results to the healthdata.be platform of Sciensano, in response to the launch of the national contact-tracing system [15]. From the end of September onwards, this laboratory data collection was also used for surveillance and replaced the COVID-19 data collection via the BSNL network. Laboratories have to record test results in their Laboratory Information System and complete the mandatory fields of the COVID-19 Laboratory-Test-Result form according to defined technical specifications [18]. The collected variables are similar to those reported for the BSNL network but include as well nominal data necessary for contact-tracing. Laboratories are required to report positive, negative and inconclusive test results of RT-PCR, antigenic and serological diagnostic tests, ideally within one to four hours after validation of the test in the laboratory [15]. The test results are collected and stored in a central COVID-19 database of the healthdata.be platform. After a data cleaning process, a subset of the test results and de-duplicated COVID-19 laboratory confirmed cases of the last seven reported days, is created. Persons can be tested more than once and therefore COVID-19 laboratory confirmed cases are de-duplicated to ensure only taking into account the true new cases. These subsets contain only an anonymous selection of variables that is pushed daily through a secured data transfer procedure and merged with the historical datasets of test results and COVID-19 laboratory confirmed cases.

Data on COVID-19 laboratory confirmed cases and performed COVID-19 diagnostic tests have been reported to the public and authorities on a daily and weekly basis by Sciensano in different epidemiological bulletins since 14 March 2020 [19], as well as via open data and on an interactive dashboard [20]. Key indicators and trends are shown (e.g. the average of new laboratory confirmed cases of the last 7 days vs. the 7 days before, the number of tests performed per day, and the evolution of the positivity ratio, by age group and geographical distribution).

\section{Testing strategy}

Testing criteria for RT-PCR testing have evolved during the course of the epidemic in Belgium, taking into account the epidemiological situation, and the available test capacity. The main testing strategies are presented in Table 1 and Fig. 2.

Table 1

Overview of the main testing strategies in Belgium since the beginning of the epidemic

\begin{tabular}{|c|c|}
\hline Timing & Strategy \\
\hline $\begin{array}{l}\text { Beginning } \\
\text { epidemic }\end{array}$ & $\begin{array}{l}\text { Testing travelers with severe respiratory symptoms returning from zone with recognized local transmission during the last } 14 \text { days or } \\
\text { symptomatic patients that has physical contact with a laboratory confirmed COVID-19 case. }\end{array}$ \\
\hline $\begin{array}{l}11 \text { March } \\
2020\end{array}$ & $\begin{array}{l}\text { Travel history dropped as criteria for testing. Exclusively testing of hospitalized cases with acute respiratory symptoms and healthcare } \\
\text { workers with acute respiratory symptoms and fever [21]. }\end{array}$ \\
\hline $\begin{array}{l}28 \text { March } \\
202\end{array}$ & Start of testing of the first cases (maximum 5) of a cluster in a nursing home fitting the case definition. \\
\hline $\begin{array}{l}8 \text { May } \\
2020\end{array}$ & Testing of all symptomatic patients that fulfilled the case definition of a possible COVID-19 case [22]. \\
\hline $\begin{array}{l}12 \text { June } \\
2020\end{array}$ & $\begin{array}{l}\text { Testing of all symptomatic patients that fulfilled the case definition of a possible COVID-19 case and high risk contacts (HRC) of a COVID- } \\
19 \text { case (one test at the moment of identification, and a second test at the end of quarantine for health care workers) [21]. }\end{array}$ \\
\hline $\begin{array}{l}13 \text { July } \\
2020\end{array}$ & Testing strategy broadened to include travelers arriving in Belgium from areas abroad considered as high risk zones (single test). \\
\hline $\begin{array}{l}21 \\
\text { October } \\
2020\end{array}$ & $\begin{array}{l}\text { Testing of asymptomatic HRC and travelers returning from high risk areas abroad temporarily put on hold, because of insufficient test } \\
\text { capacity. }\end{array}$ \\
\hline $\begin{array}{l}23 \\
\text { November } \\
2020\end{array}$ & Restart testing of asymptomatic HRC and travelers returning from high risk areas abroad. \\
\hline $\begin{array}{l}31 \\
\text { December } \\
2020\end{array}$ & $\begin{array}{l}\text { Two tests need to be performed for travelers returning from high risk areas abroad as soon as possible after arrival and at day } 7 \text { after the } \\
\text { day of return. }\end{array}$ \\
\hline $\begin{array}{l}25 \\
\text { January } \\
2021\end{array}$ & Two tests need to be performed for HRC at the moment of identification and at day 7 after the day of last high risk contact. \\
\hline
\end{tabular}

\section{Results}




\section{Number of tests}

Between the 1st of March 2020 and the 28th of February 2021, 9,487,470 tests (RT-PCR or antigen) were reported through the national laboratory based surveillance system. Figure 2 shows the number of reported tests per day during this period. The highest number of tests were performed towards the end of October, reaching 80,000 tests a day. These results represents almost only RT-PCR tests as antigen tests were not widely used in Belgium during this period (98.6\% RT-PCR, $1.4 \%$ antigen tests).

\section{Number of laboratory confirmed cases and positivity ratio}

Between the 1st of March 2020 and the 28th of February 2021 a total of 773,078 COVID-19 laboratory confirmed cases were reported. During this period two epidemic waves occurred, with the peak of the first and second wave on the 10th of April with 2,336 cases and the 27th of October 2020 with 22,214 cases respectively (Fig. 3).

\section{Turnaround time (TAT) between sampling and test result}

Figure 4 shows the evolution of the weekly percentage of tests with a test result within different timeframes after the date of sampling. Since mid-November 2020 (week 48) until the end of February 2021, a test result is available at the latest the day after sample collection for $95 \%$ of the tests performed and for more than $50 \%$ of the tests the same day.

\section{Turnaround time between test result and reporting}

Figure 5 shows the TAT between the availability of the test result and its reporting to the healthdata.be platform of Sciensano since the implementation of the central COVID-19 database for contact tracing in the beginning of May 2020 (week 19). We see an increase of the speed of reporting that remains stable since the end of August 2020 with almost $75 \%$ of test results that are reported within the same day and more than $95 \%$ that are reported at the latest the day after obtaining the test result.

\section{Turnaround time between sampling and reporting}

Combining both TAT's above, Fig. 6 shows the overall TAT between sampling and the reporting of the test result to the healthdata.be platform of Sciensano since the implementation of the central COVID-19 database for contact tracing (week 19). We see a decrease of this TAT during the summer period, an increase during the second wave at the end of October that improved again from week 44 with 90 to $95 \%$ of test results that are reported at the latest the day after sampling since week 49.

\section{Discussion}

In the context of the SARS-CoV-2 pandemic, the laboratory based surveillance of COVID-19, together with the national hospital based surveillance [23] and mortality surveillance [21], was crucial to follow the evolution of the SARS-CoV-2 epidemic in Belgium. Monitoring the number of reported COVID-19 cases and performed tests in Belgium allowed to follow-up key indicators and trends, and allowed to provide this information to the different authorities for policy making.

The participation of CML's in Belgium has been essential since the beginning of the epidemic. A rapid increasing number of CML's throughout the country were able to perform COVID-19 diagnostic tests. As a result, the number of tests performed increased significantly from March to May 2020. Because the availability of large-scale testing is crucial for monitoring the progression of the epidemic, Belgium decided to also rely on a federal platform to increase testing capacities. This combined testing strategy is halfway between the German strategy relying on a clinical laboratory network and the centralized testing approach developed by the UK government [24, 25]. Thanks to both the increasing number of laboratories performing testing and the accompanied increasing laboratory test capacity, the testing strategy could be broadened at different stages during spring 2020 . Overall, almost 10 million tests have been performed by the NRC, CML's and federal platforms over 1 year (Belgium has 11.5 million inhabitants).

These efforts done by the laboratories to increase test capacity, as well as logistic improvements (with sampling facilities and between laboratories), also resulted in an improvement of the TAT between date of sampling and laboratory test result and the speed of reporting of these results to Sciensano to be used for surveillance and to initiate contact tracing. After the first wave, from the end of April to end of May 2020 there was an improvement of the TAT between sampling and result that was followed by an improvement of the speed of reporting to Sciensano in July-August 2020. As a result, from May to the end of August 2020 the TAT between sampling and reporting improved continuously to reach more than $75 \%$ of the test results that were reported at the latest the day after the day of sampling. The second wave, with a peak in October 2020, resulted in a high number of performed tests, impacting the sampling facilities and laboratories and resulting in an increase of the TAT between sampling and test result. In this context, it was decided to prioritize and temporary stop testing of asymptomatic high-risk contacts from week 44 to week 47 . This resulted in a clear improvement again of the TAT. Following the control measures taken (most stringent measures on the 19th of October), the number of cases and the number of tests progressively declined starting from week 45 of 2020 .

Since the end of November 2020, 90 to $95 \%$ of test results are reported at the latest the day after sampling. This high performance continued in JanuaryFebruary 2021 although there was an increase in the number of tests carried out, indicating the ability of the testing facilities and laboratories to quickly process and report a high number of tests.

Despite these achievements over the past year new challenges are arising for 2021. The data collection of laboratory test results has been modified in March 2021 to allow reporting of semi-quantitative interpretation of cycle threshold (Ct) values to gain knowledge on the dynamics of the epidemic [26].

Page $4 / 10$ 
Rapid diagnostic tools such as antigenic tests will be more broadly used for testing outside laboratories settings. It is essential that positive results of these tests are reported as systematically and as quickly as the laboratory reporting. These tests however also present limitations [27] and the involvement of the

clinical laboratories will remain crucial for confirmation of test results and monitoring the laboratory test capacity and the positivity rate in 2021.

The real time integration of genomic data provided by CML's and/or large sequencing platforms is another challenge that will be crucial to better track community spread and transmission chains. Genomic data will help to identify viral mutations, and combined with health data could inform about viral genome correlations with clinical outcomes [28]. Reporting of genomic data from testing facilities to Sciensano is possible since March 2021 to take up this challenge [29].

Finally, with the start of the vaccination campaign in Belgium in 2021, laboratories will be essential for the detection and monitoring of breakthrough cases post-vaccination. We can build on the experience and all the work done during the first year of the epidemic to meet these new challenges in 2021.

\section{Conclusion}

Thanks to the effort of all laboratories and built upon an existing laboratory network, a performant exhaustive national laboratory based surveillance system to monitor COVID-19 was set up in Belgium in 2020. On top of expanding the number of laboratories performing diagnostics and significantly increasing the test capacity in Belgium, turnaround times between sampling and testing as well as reporting were optimized continuously over the first year of this pandemic.

\section{Abbreviations}

COVID-19: Coronavirus disease 2019; SARS-CoV-2: severe acute respiratory syndrome coronavirus 2; NRC: National Reference Centrum; CML: Clinical microbiology laboratory; RT-PCR: Reverse transcription polymerase chain reaction; BSNL: Belgian Sentinel Network of Laboratories; TAT: Turnaround time; Ct: Cycle threshold

\section{Declarations}

\section{Ethics approval and consent to participate}

Not applicable.

\section{Consent for publication}

Not applicable.

\section{Availability of data and materials}

The datasets supporting the conclusions of this article are available in the Epistat repository, https://epistat.wiv-isp.be/covid/ or included within the article's additional files.

\section{Competing interests}

The authors declare that they have no competing interests.

\section{Funding}

No specific funding for this study.

\section{Authors' contributions}

$M M$ and DVC drafted the manuscript. EA, AC, LW, JV, OV, SVW, AV and LC contributed to the reporting of laboratory test results to Sciensano. MM, AL, YD, ML, SK, JR, TL, ML, AC, JVB, SQ and DVC participated in data collection and reporting to the public and authorities. All authors reviewed and approved the manuscript.

\section{Acknowledgements}

We would like to sincerely thank all laboratories taking part in the surveillance and providing daily data for COVID-19 tests since the beginning of the epidemic, and by doing this greatly contributing to the management of COVID-19 in Belgium. We would also like to thank the colleagues of the healthdata.be platform of Sciensano, Kris Vrancken, Kurt Vanbrabant and Juan Quesada for the collection and processing of the data.

\section{References}

1. World Health Organization. Novel Coronavirus (2019-nCoV) SITUATION REPORT - 121 JANUARY 2020 [Internet]. 2020. Available from: https://www.who.int/docs/default-source/coronaviruse/situation-reports/20200121-sitrep-1-2019-ncov.pdf?sfvrsn=20a99c10_4

2. Singhal T. A Review of Coronavirus Disease-2019 (COVID-19). Indian J Pediatr. 2020;87:281-6. 
3. World Health Organization. Novel Coronavirus (2019-nCoV) SITUATION REPORT - 626 JANUARY 2020 [Internet]. 2020. Available from: https://www.who.int/docs/default-source/coronaviruse/situation-reports/20200126-sitrep-6-2019-ncov.pdf?sfvrsn=beaeee0c_4

4. Spiteri G, Fielding J, Diercke M, Campese C, Enough V, Gaymard A, et al. First cases of coronavirus disease 2019 (COVID-19) in the WHO European Region, 24 January to 21 February 2020. Euro Surveill. 2020;25:2000179.

5. Federal Public Service (FPS) Health, Food Chain Safety and Environment. One repatriated Belgian has tested positive for the novel coronavirus [Internet]. 2020. Available from: https://www.info-coronavirus.be/en/news/one-repatriated-belgian-has-tested-positive-for-the-novel-coronavirus/

6. Sciensano. COVID-19 - SITUATION EPIDEMIOLOGIQUE AU 14 MARS 2020 [Internet]. Sciensano; 2020 Mar. Available from: https://covid19.sciensano.be/sites/default/files/Covid19/COVID-19_Daily\%20report_20200314\%20-\%20FR.pdf

7. Muyldermans G, Ducoffre G, Leroy M, Dupont Y, Quolin S, Participating Sentinel Laboratories T, et al. Surveillance of infectious diseases by the Sentinel Laboratory Network in Belgium: 30 years of continuous improvement. PLOS ONE. 2016;11.

8. Walckiers D, Stroobant A, Yourassowsky E, Lion J, Cornelis R. A sentinel network of microbiological laboratories as a tool for surveillance of infectious diseases in Belgium. Epidemiol Infect. 1991;106:297-303.

9. Weemaes M, Martens S, Cuypers L, Van Elslande J, Hoet K, Welkenhuysen J, et al. Laboratory information system requirements to manage the COVID19 pandemic: A report from the Belgian national reference testing center. J Am Med Inform Assoc JAMIA. 2020;27:1293-9.

10. Hoxha A, Wyndham-Thomas C, Klamer S, Dubourg D, Vermeulen M, Hammami N, et al. Asymptomatic SARS-CoV-2 infection in Belgian long-term care facilities. Lancet Infect Dis. 2020;

11. Sciensano. COVID-19 surveillance frequently asked questions [Internet]. 2021. Available from: https://covid19.sciensano.be/sites/default/files/Covid19/COVID-19_FAQ_ENG_final.pdf

12. Capron A. LIJST VAN LABORATORIA MET DIAGNOSTIEK VOOR COVID-19 [Internet]. 2020. Available from: https://covid19.sciensano.be/sites/default/files/Covid19/COVID-19_Diagnostic_Labs_NL.pdf

13. Berger N, Muyldermans G, Dupont Y, Quoilin S. Assessing the sensitivity and representativeness of the Belgian Sentinel Network of Laboratories using test reimbursement data. Arch Public Health. 2016;74:29.

14. Sciensano. Peillaboratoria [Internet]. 2020. Available from: https://nrchm.wiv-isp.be/nl/peillabo/default.aspx

15. Van Oyen H, De Cock J. OMZENDBRIEF AAN LABORATORIA 20 juli 2020 - De verplichte rapportage van PCR/antigeen en serologische resultaten in het kader van de COVID-19-pandemie [Internet]. 2020. Available from: https://covid-19.sciensano.be/sites/default/files/Covid19/COVID19_communication_reporting_labs_to_contacttracing_20200720_NL.pdf

16. Sciensano. Erkenningsprocedure van de medische laboratoria erkend door de FOD volksgezondheid voor het uitvoeren van de COVID-19 screeningstest met moleculair biologische technieken [Internet]. 2020. Available from: https://covid-19.sciensano.be/sites/default/files/Covid19/COVID19_procedure_lab-accreditation_NL.pdf

17. RIZIV. Omzendbrief laboratoria - Terugbetaling opsporingstesten Coronavirus tijdens de Covid-19 pandemie [Internet]. 2020. Available from: https://covid-19.sciensano.be/sites/default/files/Covid19/Omzendbrief\%2019\%20mei\%20-\%200psporingstesten\%20COVID-19.pdf

18. healthdata.be. DATABASE COVID-19 TESTRESULTS - Technical guidelines [Internet]. 2020. Available from: https://covid19lab.healthdata.be/softwaresolutions/technical-guidelines

19. Sciensano. COVID-19 - Epidemiologische situatie [Internet]. 2021. Available from: https://covid-19.sciensano.be/nl/covid-19-epidemiologische-situatie

20. Sciensano. Belgium COVID-19 Epidemiological Situation [Internet]. 2021. Available from: https://datastudio.google.com/embed/reporting/c14a5cfccab7-4812-848c-0369173148ab/page/ZwmOB

21. Bustos Sierra N, Bossuyt N, Braeye T, Leroy M, Moyersoen I, Peeters I, et al. All-cause mortality supports the COVID-19 mortality in Belgium and comparison with major fatal events of the last century. Arch Public Health. 2020;78:117.

22. Regeringscommissariaat Corona. Note: stratégies de testing / Testing strategie [Internet]. 2020. Available from: https://www.uvcw.be/no_index/files/4592-2020-10-29--quarantaine-imcvg_teststrategie-note-commissariat.pdf

23. Van Goethem N, Vilain A, Wyndham-Thomas C, Deblonde J, Bossuyt N, Lernout T, et al. Rapid establishment of a national surveillance of COVID-19 hospitalizations in Belgium. Arch Public Health. 2020;78:121.

24. Banatvala J. COVID-19 testing delays and pathology services in the UK. The Lancet. Elsevier; 2020;395:1831.

25. Kluge S, Janssens U, Welte T, Weber-Carstens S, Marx G, Karagiannidis C. German recommendations for critically ill patients with COVID-19. Med Klin Intensivmed Notfallmedizin. 2020;1-4.

26. Sciensano. RAG INTERPRETATION AND REPORTING OF SARSCOV-2 PCR RESULTS [Internet]. 2020. Available from: https://covid19.sciensano.be/sites/default/files/Covid19/20201208_Advice\%20RAG\%20Interpretation\%20and\%20reporting\%20of\%20COVID\%20PCR\%20results.pdf

27. Schildgen V, Demuth S, Lüsebrink J, Schildgen O. Limits and opportunities of SARS-CoV-2 antigen rapid tests - an experience based perspective. medRxiv. Cold Spring Harbor Laboratory Press; 2020;2020.09.22.20199372.

28. Vandenberg O, Martiny D, Rochas O, van Belkum A, Kozlakidis Z. Considerations for diagnostic COVID-19 tests. Nat Rev Microbiol. Nature Publishing Group; 2021;19:171-83.

29. healthdata.be (Sciensano). DATABASE COVID-19 TESTRESULTS [Internet]. Available from: https://covid19lab.healthdata.be/datacollection/laboratorytestresult

\section{Figures}

Page 6/10 
First Belgian COVID-19 infection, testing by NRC
CML's start testing for COVID-19, confirmation positive samples by NRC
Federal platform evolves to a new platform
CML's start to directly report test results to Sciensano
Central COVID-19 database used for surveillance

Set-up of federal testing platform

Sending of test results to central COVID-19 database becomes mandatory
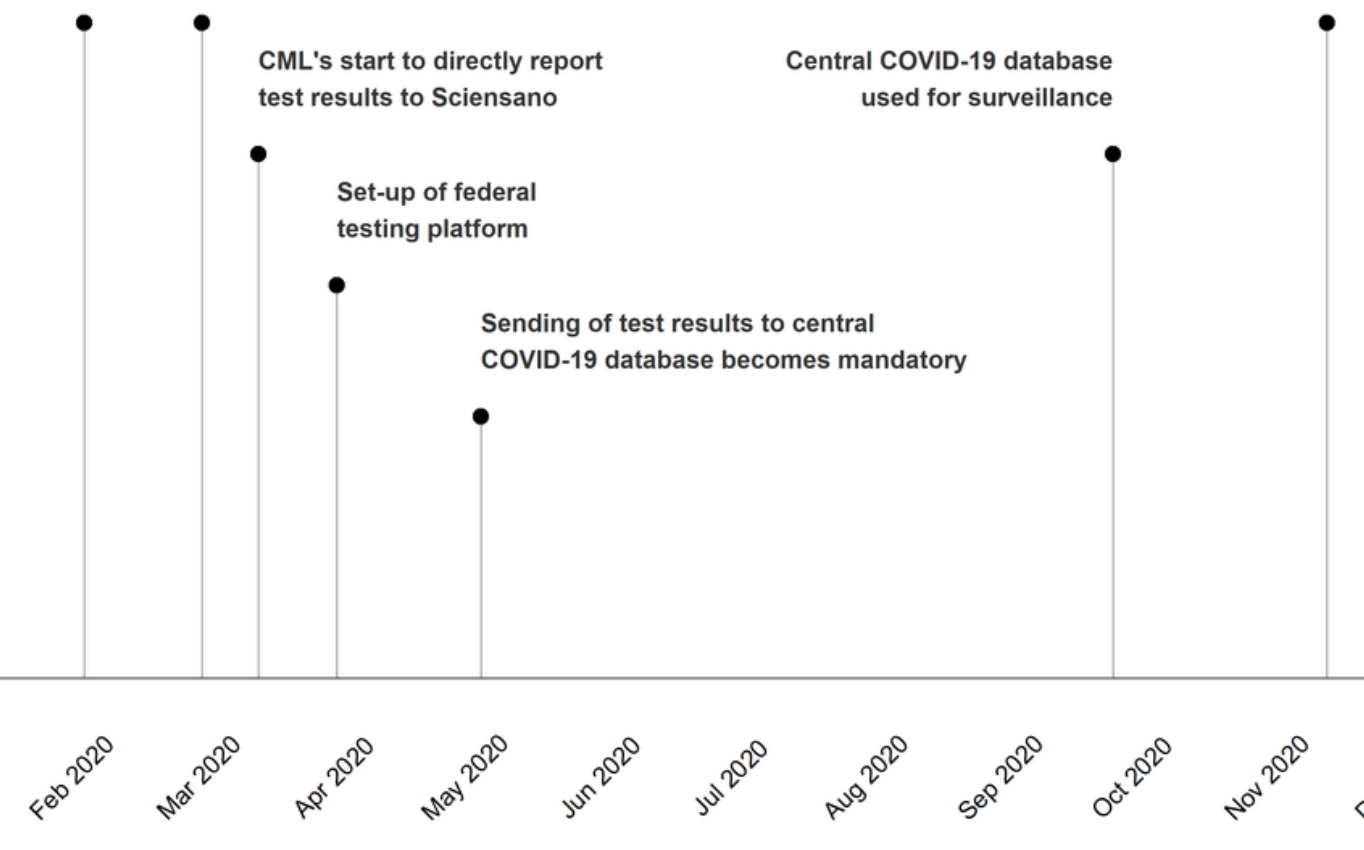

$+a^{2}$
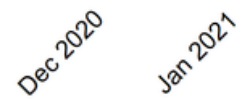

$<e^{2^{22^{2}}}$

Figure 1

Overview of the laboratory based surveillance outline since the beginning of 2020 until February 2021

Testing symptomatic patients with a specific travel history

Testing symptomatic hospitalised patients and healthcareworkers

Testing symptomatic patients that fulfilled the case definition of a possible COVID-19 case

Testing possible COVID-19 cases and high-risk contacts

Testing possible COVID-19 cases, high-risk contacts and travelers returning from high-risk zones

Testing of high-risk contacts and travelers returning from high-risk zones put on hold

Testing twice high-risk contacts (25/01/2021) and travelers returning from high-risk zones (31/12/2020)

at the beginning and the end of quarantine

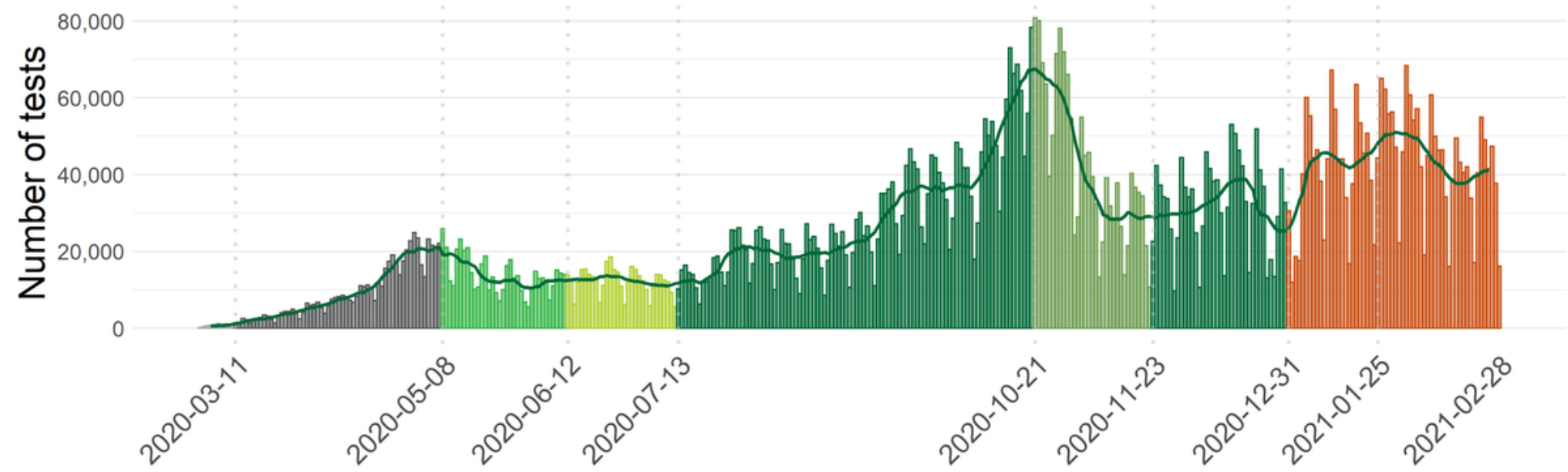

Figure 2

Number of COVID-19 diagnostic tests reported per day (bars colored regarding the implemented testing strategy) and the moving average over seven centered days (dark green line) per date of test result, from the 1st of March 2020 until the 28th of February 2021, Belgium. 


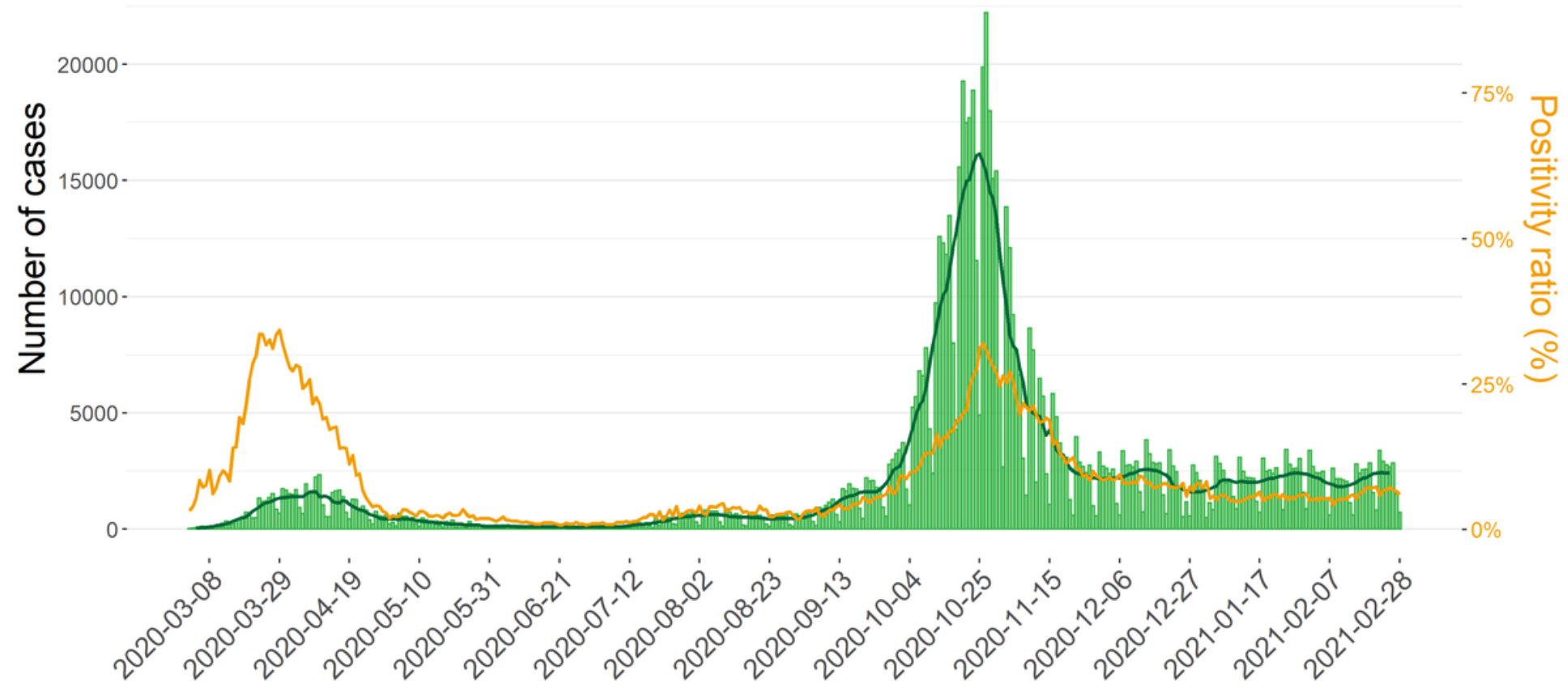

Figure 3

Daily number of COVID-19 laboratory confirmed cases (light green bars), the moving average over seven days (dark green line) and positivity ratio (orange line), from the 1st of March 2020 until the 28th of February 2021, Belgium

Same day $\square$ Next day $\square$ Day $+2 \square$ Later

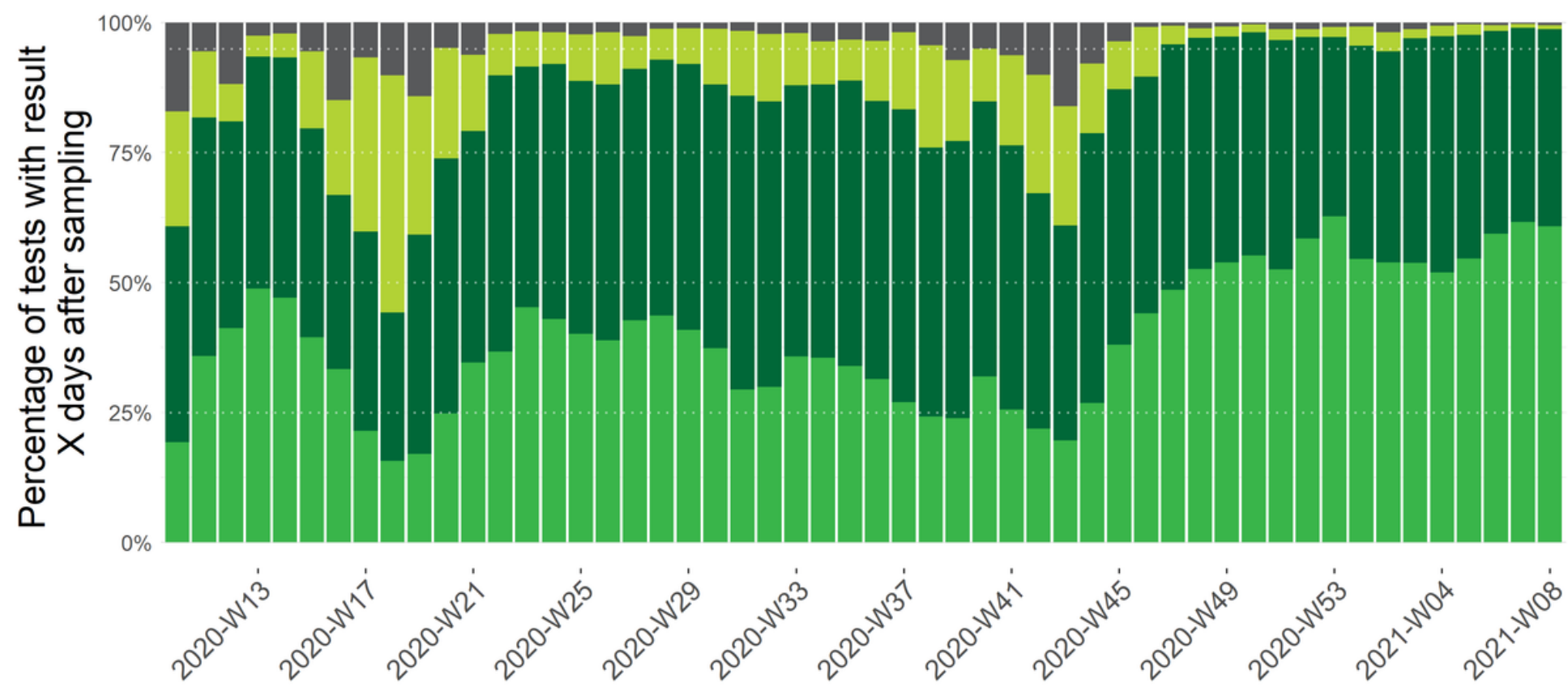

Figure 4

Weekly percentage of tests colored by delay between date of sampling and date of test result, from the 1st of March 2020 (week 10) until the 28th of February 2021 (week 08). 
Same day $\square$ Next day Day $+2 \square$ Later

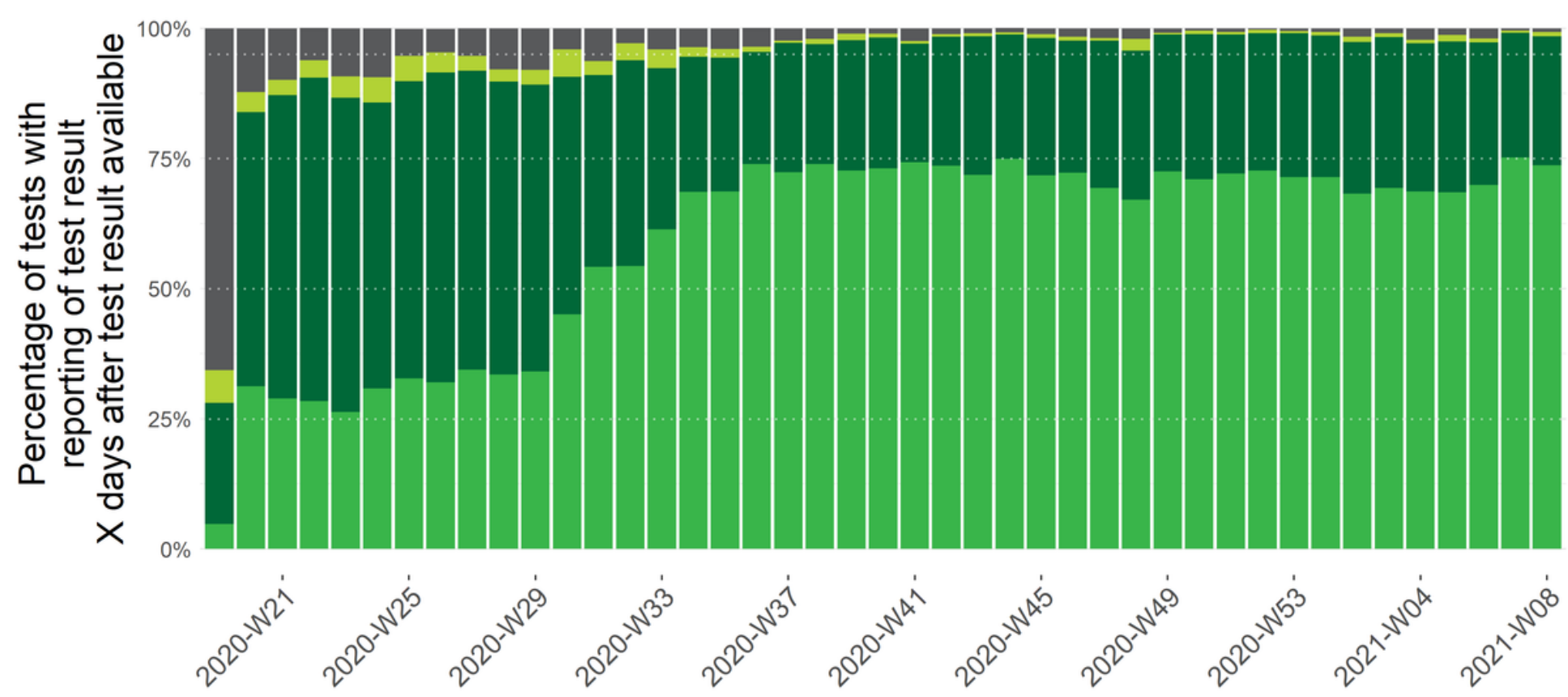

Figure 5

Weekly percentage of tests colored by delay between date that the test result is available and date of reporting of the test result, from the 5 th of May 2020 (week 19) until the 28th of February 2021 (week 08).

Same day $\square$ Next day $\square$ Day $+2 \square$ Later

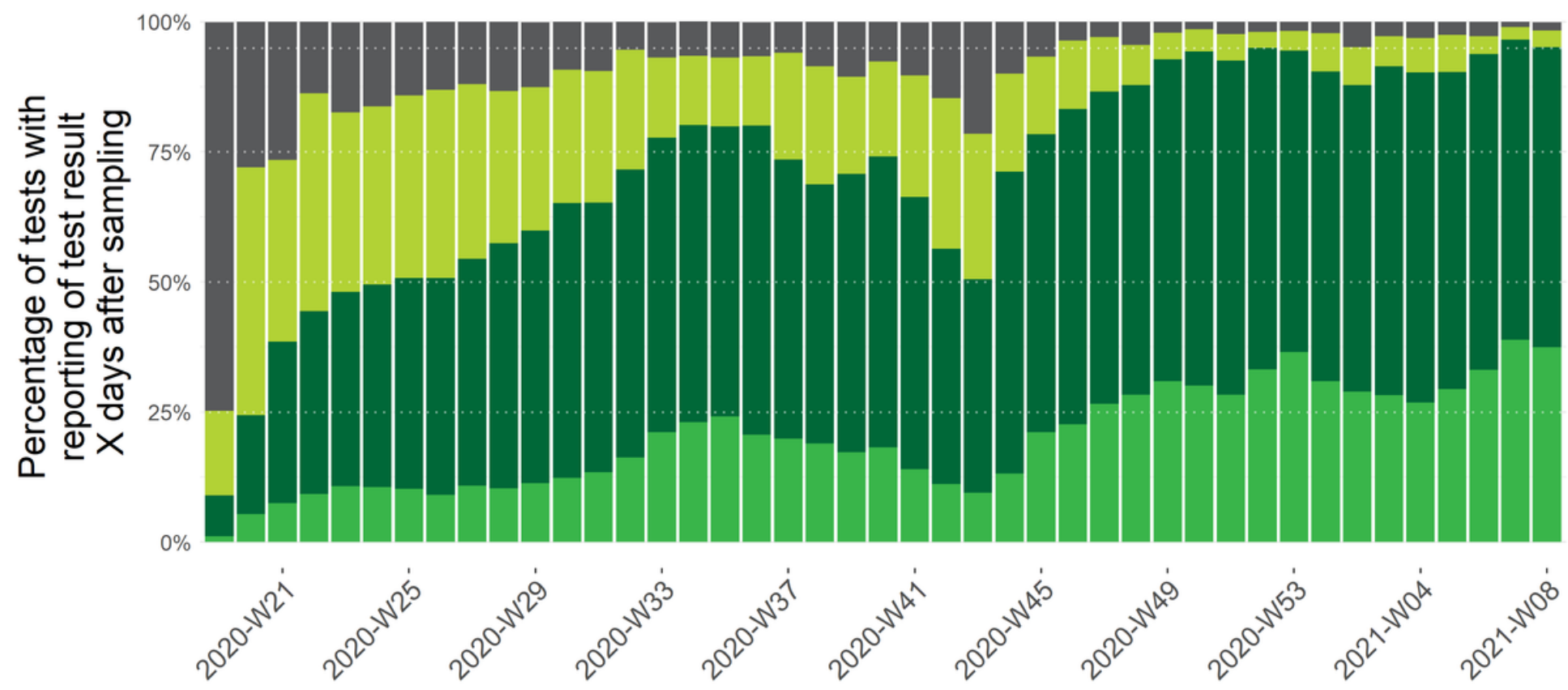

Figure 6

Weekly percentage of tests colored by delay between date of sampling and date of reporting of the test result, from the 5 th of May 2020 (week 19 ) until the 28th of February 2021 (week 08).

\section{Supplementary Files}

This is a list of supplementary files associated with this preprint. Click to download. 
- Additionalfile1.xls

- Additionalfile2.xls

- Additionalfile3.xls

Page 10/10 